\title{
1 To cite:
}

2 Tilga, H., Hein, V., Koka, A., \& Hagger, M. S. (2019). How physical education teachers'

3 interpersonal behaviour is related to students' health-related quality of life. Scandinavian Journal

4 of Educational Research. Advance online publication. doi: $\underline{10.1080 / 00313831.2019 .1595718}$

5

6 How Physical Education Teachers' Interpersonal Behaviour is Related to Students' Health-

\section{Related Quality of Life}

8

$11{ }^{1}$ Institute of Sport Sciences and Physiotherapy, Faculty of Medicine, University of Tartu, Tartu,

12 Estonia

$13 \quad{ }^{2}$ School of Psychology, Curtin University, Perth, Australia

$14{ }^{3}$ Faculty of Sport and Health Sciences, University of Jyväskylä, Jyväskylä, Finland

15

16

Author Note

17 Correspondence regarding this article should be addressed to Henri Tilga. Institute of Sport

18 Sciences and Physiotherapy, Faculty of Medicine, University of Tartu, 4 Ujula St., Tartu, Tartu

19 county 51008, e-mail: henri.tilga@ut.ee 


\section{Abstract}

2 Grounded in self-determination theory (SDT), this cross-sectional study tested relations of

3 students' perceptions of autonomy-supportive and controlling behaviour from teachers in

4 physical education with students' health-related quality of life (HRQoL), and the potential role of

5 students' perceived need satisfaction and need frustration as a mediator of these relationships.

6 School students $(\mathrm{N}=1031)$ completed self-report measures of perceived autonomy support,

7 perceived teachers' controlling behaviour, students' need satisfaction and need frustration, and

8 HRQoL. Results indicated that students' perceptions of autonomy support from teachers was

9 positively associated with HRQoL through need satisfaction. Students' perceptions of controlling

10 behaviour from teachers was negatively related with HRQoL through need frustration. There was

11 no significant association between autonomy support and need frustration, or between

12 controlling behaviour and need satisfaction. Findings provide evidence that perceived autonomy

13 support and controlling behaviour from the teacher in PE contributes to students' HRQoL

14 through unique pathways.

15 Key Words: autonomy support, controlling behaviour, psychological needs, health-related quality 16 of life. 


\section{How Physical Education Teachers' Interpersonal Behaviour is Related to Students' Health- Related Quality of Life}

Health-related quality of life (HRQoL) among adolescents has received increased attention in the research literature on child and adolescent health given the importance of this construct to overall health, psychological well-being, and optimal functioning (Bisegger et al., 2005; Meade \& Dowswell, 2016). HRQoL is described as “a person’s subjective evaluations of the influences of their current health status, health care, and health promoting activities on their ability to achieve and maintain a level of overall functioning that allows them to pursue valued life goals and that is reflected in their general well-being" (Shumaker \& Naughton, 1995, p. 7). HRQoL has also been considered an important outcome in pediatric population health as it encompasses a wide set of health concerns such as physical, social, emotional, and academic functioning (Varni, Burwinkle, Seid, \& Skarr, 2003). In particular, research suggests that HRQoL is likely to be an important correlate of school performance (Durlak, Weissberg, Dymnicki, Taylor, \& Schellinger, 2011). While the primary goal of physical education (PE) is to provide children with skills that improve physical literacy, skills, and competencies, an increasingly important associated goal is to promote better physical and psychological health and, related to this goal, better subjective well-being and quality of life. With appropriate support and guidance from the PE teacher, PE can provide opportunities for students to develop behaviours that promote a healthy lifestyle, experience feelings of physical and emotional wellbeing arising from physical activity, and foster social interaction with classmates. Taken together, these experiences derived from the 'health promotion' goal of PE are likely to result in better HRQoL in students. 

adolescents' HRQoL (Standage \& Gillison, 2007; Standage, Gillison, Ntoumanis, \& Treasure, 2012). This is based on the premise that what teachers say and do in PE lessons can have a

4 profound influence on students' motivation and other health outcomes (Reeve \& Jang, 2006). In

5 particular, behaviours displayed by teachers, and students' interpretation of them, may signal

6 support for motivation toward key behaviours in PE. For example, research based on self-

7 determination theory (SDT; Deci \& Ryan, 2000; Ryan \& Deci, 2017), has shown that students'

8 perceptions that their teachers support their autonomy is related to their HRQoL (Koka, 2014;

9 Standage \& Gillison, 2007; Standage et al., 2012). According to SDT, support for autonomy in specific behavioural contexts is important because it provides students with a sense of ownership

11 and responsibility for their behaviour, and is related to engagement, interest and enjoyment in the

12 behaviour and, critically, persistence. Students' perceptions of autonomy support reflect the

13 behaviours that teachers display in lessons that support student autonomy such as conveying

14 confidence in students' ability to do well or listening to students (Reeve \& Halusic, 2009).

15 Students that view their teachers as autonomy supportive are not only more likely to report better 16 HRQoL, but are also more likely to persist with behaviours that may promote better well-being

17 (e.g., Standage et al., 2012). Relations between perceived autonomy support on quality of life is 18 proposed to be attributable to psychological need satisfaction (Deci \& Ryan, 2000).

However, it is important to note that teachers may also exhibit controlling interpersonal

20 behaviours in PE lessons. This is likely reflected in students' perceptions of their teacher as 21 controlling. Previous research has shown small-to-medium sized relations between displays of 22 autonomy-supportive and controlling behaviours by social agents operating in various contexts 23 (e.g., sport, and PE; Bartholomew, Ntoumanis, Ryan, Bosch, \& Thøgersen-Ntoumani, 2011; 
1 Tessier, Sarrazin, \& Ntoumanis, 2008). This means that these types of behaviour may be

2 independent. In addition, teachers may be inconsistent in their display of these different sets of

3 teaching behaviours. For example, teachers may use autonomy-supportive behaviours such as

4 listening to students and responding to them when they express their opinion, but may also use

5 threat of punishment to keep students in line during lessons, a controlling behaviour. Recently,

6 several studies have demonstrated that students' perceptions of controlling behaviours are related

7 to their need frustration, which, in turn, are related to maladaptive outcomes like controlled

8 motivation and amotivation (Haerens, Aelterman, Vansteenkiste, Soenens, \& Van Petegem,

92015 ) or anger (Hein, Koka, \& Hagger, 2015). Such behaviours may, therefore, serve to

10 undermine students' autonomous motivation and well-being. However, there are no studies to

11 date that have examined the relationship between students' perceptions of their teachers'

12 controlling behaviour and their HRQoL, and whether this relationship is mediated by need

13 frustration. In the current study we aimed to fill this gap by testing whether or not relations

14 between students' perception of teachers' controlling behaviour and HRQoL is mediated by need

15 frustration. This is contrasted with the mediated relationship between students' perceptions of

16 their teachers' autonomy support and their HRQoL through need satisfaction (e.g., Koka, 2014;

17 Standage et al., 2012).

$18 \quad$ Theoretical Framework

SDT has been widely used to explain the influence of social-contextual factors on human

20 psychological experiences and behaviour across multiple contexts (Deci \& Ryan, 2000),

21 including educational contexts (Van de Berghe, Vansteenkiste, Cardon, Kirk, \& Haerens, 2014;

22 Pihu, Hein, Koka, \& Hagger, 2008). One of the most prominent sub-theories of SDT is basic

23 psychological needs theory (BPNT; Deci \& Ryan, 2002). According to BPNT, humans have 
1 fundamental, basic psychological needs: the need for autonomy (i.e., to feel self-determined in one's actions rather than feeling controlled), the need for competence (i.e., to feel competent in interactions with the environment and experience opportunities in which to express their capabilities), and the need for relatedness (i.e., to feel a secure sense of belongingness and connectedness to others) (Deci \& Ryan, 1985, 2000; Sheldon, Elliot, Kim, \& Kasser, 2001). Individuals strive to satisfy three needs in their everyday actions, and fulfilment of these needs is related to optimal psychological well-being (e.g., Mouratidis, Vansteenkiste, Sideridis, \& Lens, 2011). However, if these needs are frustrated (De Meyer et al., 2014), people are more likely to experience activities as controlled by external events or contingencies, and express sub-optimal functioning, ill-being, and maladaptive outcomes (Bartholomew et al., 2011; De Meyer, Soenens, Aelterman, De Bourdeaudhuij, \& Haerens et al., 2016; Vansteenkiste \& Ryan, 2013). In the school context, the extent to which students perceive that their needs are satisfied or frustrated is partly dependent on the interpersonal behaviours adopted by their teachers. According to BPNT, teachers' behaviour can be viewed in terms of the extent to which they support student autonomy and, therefore, whether their actions facilitate satisfaction of students' psychological needs. Teachers behaviours can, therefore, be viewed as autonomy supportive and need satisfying, or controlling and need frustrating. The concept of autonomy support is characterised by authoritative agents (e.g., teachers, leaders, managers) adopting specific behaviours that support and promote autonomy among the groups for whom they are responsible (e.g., students, staff, employees). Autonomy-supportive behaviours include adopting the perspectives and feelings of students, giving a rationale for tasks, providing choice, and encouraging self-endorsed action (Deci, Eghrari, Patrick, \& Leone, 1994; Jang, Reeve, \& Deci, 2010; McLachlan \& Hagger, 2010; Reeve \& Jang, 2006). Optimal well-being and healthy 
1 functioning are facilitated if needs for autonomy, competence, and relatedness are met within a

2 social context (Ryan \& Deci, 2008). According to SDT (Ryan \& Deci, 2017), autonomy-

3 supportive behaviour is particularly important because it facilitates satisfaction of all three basic

4 psychological needs. Students' perceptions of their teachers' behaviour is critical in this regard.

5 Studies have found that students that perceive their teachers displaying autonomy-supportive

6 behaviours are more likely to report adaptive affective and behavioural outcomes such as

7 concentration in the PE classes and intention to participate in optional PE (Ntoumanis, 2005),

8 physical self-esteem and effort (Hein \& Caune, 2014), and also HRQoL (Koka, 2014; Standage

9 \& Gillison, 2007; Standage et al., 2012). The proposed mechanism for this effect is via the

10 student's perceptions of satisfaction of psychological needs and autonomous motivation, which

11 serve to mediate effects of perceived autonomy support on outcomes.

Consistent with SDT, teachers may also display controlling behaviours in school lessons.

13 Controlling behaviour from teachers can be characterised by using pressuring tactics to make

14 students think, feel, or behave as required, with disregard to students' opinions and needs

15 (Reeve, 2009). Such behaviours are likely to undermine autonomous motivation and lead to

16 maladaptive outcomes such as anxiety (Assor, Kaplan, Kanat-Maymon, \& Roth, 2005),

17 depersonalisation (Soenens, Sierens, Vansteenkiste, Dochy, \& Goossens, 2012), oppositional

18 defiance (Haerens et al., 2015), and anger and bullying (Hein et al., 2015). The mechanism for

19 these relations is through students' perceived frustration of psychological needs and controlled

20 motivation. It is important to note that teachers' could display both controlling and autonomy-

21 supportive behaviours within a single lesson (Amoura, Berjot, Gillet, Caruana, \& Finez, 2015).

22 Haerens et al. (2015) demonstrated that students' perceptions of their teachers' behaviour as

23 autonomy-supportive and controlling were related to adaptive and maladaptive motivational 
outcomes through separate pathways. Specifically, relationships between of students' perception

of teachers' autonomy-supportive teaching was indirectly related to adaptive motivational outcomes (i.e., autonomous motivation) in PE through need satisfaction, whereas students'

perception of teachers' controlling behaviour was indirectly related to maladaptive motivational outcomes (i.e., controlled motivation and amotivation) in PE through need frustration. Despite this evidence, there has been little attention paid to the relationship between students' perceptions of their PE teachers' interpersonal behaviour (i.e., autonomy-supportive and controlling behaviours) and their HRQoL.

\section{The Present Study}

Previous research has highlighted that the relationship between students' perception of teachers' support for their autonomy on their HRQoL in PE is mediated by psychological need satisfaction (Koka, 2014; Standage \& Gillison, 2007; Standage et al., 2012). However, the processes by which students' perception of teachers' controlling behaviour relates to students' HRQoL has not been previously tested and warrants further investigation. We consider the possibility that students' perception of their teachers' controlling behaviour will be negatively related to their need satisfaction and HRQoL. Importantly, we aim to test the independence of these two indirect effects ${ }^{1}$. Such a test would enable us to demonstrate the pathways by which students' perceptions of their teachers' autonomy-supportive and controlling behaviour in PE affect their HRQoL. In the present study, in line with previous research in PE (Haerens et al., 2015), we tested a model based on SDT in which students' perceptions that their teachers'

\footnotetext{
${ }^{1}$ It is important to note that reference to indirect effects in the current study should not be taken to infer causal relations. The term used here is consistent with the analytic methods used - it is typical to refer to mediated relations between an independent variable (e.g., students' perception of their teachers' controlling behaviour) and a dependent variable (e.g., students' HRQoL) via a mediator (e.g., psychological need satisfaction) in regression or path analysis as an "indirect effect" (Hayes, 2018). Causal relations can only be inferred through the type of data used, not the analytic method.
} 
1 autonomy-supportive and controlling behaviour was expected to be related to their HRQoL in

2 separate indirect effects. The hypothesised model is presented in Figure 1. First, we predicted

3 that students' perception of their teachers' autonomy-supportive behaviour in PE would be

4 indirectly related to their HRQoL through psychological need satisfaction (H1). Second, we

5 hypothesised that students' perception of teachers' controlling behaviour in PE would be

6 indirectly related to their HRQoL through psychological need frustration (H2). Third, we

7 predicted that teachers' autonomy-supportive behaviour would be negatively related to

8 psychological need frustration (H3), and teachers' controlling behaviour would be negatively

9 related to psychological need satisfaction (H4), consistent with previous research (Bartholomew

10 et al., 2011; Haerens et al., 2015). However, relationships H3 and H4 were expected to be less

11 pronounced than relationships $\mathrm{H} 1$ and $\mathrm{H} 2$. Finally, in line with previous studies showing that

12 motivational processes in PE are largely invariant across gender (e.g., Standage, Duda, \&

13 Ntoumanis, 2005; Standage et al., 2012) and age (Wang, 2012), we expected our hypothesised

14 model also to be invariant across gender and grade groups (H5).

[Figure 1 near here]

\section{Method}

\section{Participants and Procedure}

Participants in the current study comprised 1031 secondary school students (448 boys and

19583 girls), aged between 12 and 15 years $\left(M_{\text {age }}=13.39 ; S D=1.02\right)$ from the same cultural

20 group, who share a common ethnicity and language. The students were enrolled from randomly

21 selected schools in Estonia. Students participated in mandatory PE lessons twice per week.

22 Information about the survey was provided to students by their class teachers, and the survey was

23 completed via the internet with a unique url generated for each student. The purpose of the 
1 research and instructions for completing the questionnaire were provided on the survey landing

2 page. Students were also informed that their responses would be confidential and anonymous and

3 were required to complete an informed consent form prior to completing the questionnaire.

4 Approval to conduct the study was received from the head-teacher and students' parents in

5 advance of data collection. The Ethical Committee of Tartu University approved the study

6 protocol.

$7 \quad$ Measures

\section{Teachers' Autonomy-Supportive Behaviour}

9 Students' perception of teachers' autonomy-supportive behaviour was measured using

10 the multidimensional perceived autonomy support scale for physical education (MD-PASS-PE;

11 Tilga, Hein, \& Koka, 2017). Students were presented with a common stem: "My PE teacher...",

12 followed by the items tapping the three subscales: organisational autonomy support (e.g., “...

13 allows me to choose exercise place"), procedural autonomy support (e.g., "... explains the effect

14 of exercises”), and cognitive autonomy support (e.g., “... understands my needs”). Each subscale

15 comprised five items with responses provided on 7-point scales $(1=$ strongly disagree and $7=$

16 strongly agree). Previous research has supported the factor structure and reliability of the current

17 measure (Tilga et al., 2017).

18 Teachers' Controlling Behaviour

An adapted version (Hein et al., 2015) of the multidimensional controlling coach

20 behaviours scale (CCBS; Bartholomew, Ntoumanis, \& Thøgersen-Ntoumani, 2010) was used to

21 measure the students' perception of the PE teachers' controlling behaviour. Students were

22 presented with a common stem: "My PE teacher...", followed by the items tapping the three

23 CCBS subscales: negative conditional regard (e.g., “... pays me less attention if I have displeased 
1 him/her”), intimidation (e.g., “... uses the threat of punishment to keep me in line during

2 lesson”), and the controlling use of grades (e.g., “... promises to give me a good grade if I do

3 well”). Each subscale comprised three items with responses provided on 7-point scales $(1=$

4 strongly disagree and $7=$ strongly agree). Previous studies have supported the factorial validity

5 of the adapted version of the CCBS as well as the acceptable reliability of the scales (Hein et al.,

6 2015; Hein, Emeljanovas, \& Mieziene, 2018).

7 The Need Satisfaction and Need Frustration Scale

8 Students' perceptions of need satisfaction and need frustration in PE were assessed by the

9 basic psychological need satisfaction and need frustration scale (BPNSNF; Chen et al., 2015)

10 adapted and validated for PE (Haerens et al., 2015). Each subscale comprised four items and was

11 presented with a common stem ("During the PE lesson...") followed by the set of items: need

12 satisfaction for autonomy (e.g., “...I felt that the exercises reflect what I really want”),

13 competence (e.g., "...I felt capable at what I did"), and relatedness (e.g., "...I felt that the class

14 members I care about also cared about me”), and need frustration for autonomy (e.g., “...I felt

15 pressured to do too many exercises”), competence (e.g., “...I felt insecure about my abilities”),

16 and relatedness (e.g., “...I felt excluded from the group I want to belong to”). Participants'

17 responses were provided on 7-point scales $(1=$ strongly disagree and $7=$ strongly agree $)$.

$18 \quad H R Q o L$

Students’ HRQoL was measured using an adapted, validated version (Viira \& Koka,

20 2011) of the 23-item pediatric quality of life inventory 4.0 generic core scales (PedsQL ${ }^{\mathrm{TM}} 4.0$;

21 Varni, Seid, \& Kurtin, 2001). The PedsQL ${ }^{\mathrm{TM}} 4.0$ comprises five dimensions: physical health

22 (eight items, e.g., "I have low energy"), social functioning (five items, e.g., "I have trouble

23 getting along with other kids"), emotional functioning (five items, e.g., "I feel angry"), school- 
1 related functioning (three items, e.g., "I forget things"), and days missed from school due to

2 illness (two items, e.g., "I miss school because of not feeling well"). Students were asked to

3 indicate how much of a problem has this been during the past one month. Responses were

4 provided on 5 -point scales $(0=$ strongly disagree and $4=$ strongly agree $)$. Prior to data analysis,

5 items were reverse-scored and linearly transformed to a $0-100$ scale $(0=100,1=75,2=50,3$

$6=25$, and $4=0$ ). Previous studies have supported the factorial validity of PedsQL ${ }^{\mathrm{TM}} 4.0$ as well

7 as the reliability of total score of HRQoL (e.g., Koka, 2014; Standage et al., 2012).

\section{Data Analysis}

The SPSS Version 23.0 and AMOS Version 23.0 statistical packages were used to analyse the data. Multiple goodness-of-fit indices suggested by $\mathrm{Hu}$ and Bentler (1999) were used

11 to evaluate fit of the proposed factor structure of the scales with the data. The following indices

12 were used: the comparative fit index (CFI), the Bentler-Bonett non-normed fit index (NNFI), 13 and the root mean square error of approximation (RMSEA). An acceptable fit of the data with 14 the hypothesised model is indicated by values $\geq .90$ for the CFI and NNFI, and value $\leq .08$ for 15 the RMSEA (Hu \& Bentler, 1999).

In the first stage of our analyses, we conducted a series of separate confirmatory factor

17 analyses (CFAs) to test the adequacy of the proposed factor structure of the scales used to tap study constructs. Next, composite scores for the cognitive, procedural, and organisational autonomy support; negative conditional regard, controlling use of grades, and intimidation; autonomy, competence, and relatedness satisfaction; autonomy, competence, and relatedness

21 frustration; physical health, social functioning, emotional functioning, school-related

22 functioning, and days missed from school due to illness constructs were calculated as the average

23 of the item scores for each scale. Latent autonomy support, controlling behaviour, need 
1 satisfaction, and need frustration constructs were indicated by the three composite variables for each latent construct, and the latent HRQoL construct was indicated by five composite variables for the physical health, social functioning, emotional functioning, school-related functioning, and days missed from school due to illness scales.

We followed the following procedure to test study hypotheses. First, the adequacy of data fit for the measurement confirmatory factor analytic model with five latent constructs and 17 indicators was estimated. This step is important to ensure the discriminant validity of the study measures and confirm their treatment as separate constructs in the proposed model (Anderson \& Gerbing, 1988; Hagger, 2014). Next, a structural equation model in which direct paths from autonomy support and controlling behaviour to HRQoL, and the indirect paths from autonomy support through need satisfaction to HRQoL, and from controlling behaviour through need frustration to HRQoL, were estimated. We also specified the direct path from autonomy support to need frustration, and from controlling behaviour to need satisfaction. In addition, the structural model included correlations between autonomy support and controlling behaviour, and a correlation between the disturbance terms, also known as errors in prediction, of need satisfaction and need frustration. Parameter estimates and bias-corrected bootstrapped confidence intervals were calculated for each of the proposed pathways consistent with recommendations (Cerin \& MacKinnon, 2008; Hayes \& Scharkow, 2013). Finally, we tested whether or not our proposed model was invariant across gender and grade following the invariance routine recommended by Byrne (2010). An initial unconstrained model was compared to successive constrained models to examine the equality of factor loadings, intercepts, structural paths, and structural covariances across grade and gender groups. Changes in CFI and NNFI values of .01 or less was considered indicative of invariance of each set of parameters in the routine, as 
1 suggested by Cheung and Rensvold (2002) and Widaman (1985). The data file and analysis

2 scripts are available online at https://osf.io/fb74u/

\section{Results}

\section{Preliminary Analysis}

The online survey required participants to respond to all items; thus, there was no missing data. In total, 1031 participants provided complete data suitable for statistical analysis. Results of a series of confirmatory factor analyses for each of the study measures demonstrated acceptable goodness-of-fit statistics: MD-PASS-PE $(\mathrm{CFI}=.94$; NNFI = .92; RMSEA = .08), CCBS $(\mathrm{CFI}=$ $.97 ; \mathrm{NNFI}=.96 ; \mathrm{RMSEA}=.06), \mathrm{BPNSNF}(\mathrm{CFI}=.94 ; \mathrm{NNFI}=.93 ; \mathrm{RMSEA}=.06)$, and PedsQL ${ }^{\mathrm{TM}} 4.0(\mathrm{CFI}=.92 ; \mathrm{NNFI}=.91 ; \mathrm{RMSEA}=.05)$. We estimated the skewness and kurtosis estimates of each item, which ranged between -2 to +2 and were considered acceptable to support normal univariate distribution (George \& Mallery, 2010). However, Mardia's normalised coefficient value indicated deviations from multivariate normality $(48.01$, critical ratio $=34.13)$. As a consequence, we used a bootstrapping procedure to provide a more accurate estimation of the parameter estimates (Byrne, 2010; Preacher \& Hayes, 2008). Descriptive statistics including non-latent correlations among averaged scales, and Cronbach's $\alpha$ reliability coefficients for all the scales, are presented in Table 1. Correlations among latent study variables are presented in Table 2.

[Table 1 near here]

[Table 2 near here]

\section{Main Analysis}

An initial fit of the measurement model fell short of acceptable fit according to the multiple criteria adopted: $\chi^{2}=1046.99, \mathrm{df}=109, p<.001 ; \mathrm{CFI}=.89 ; \mathrm{NNFI}=.86 ; \mathrm{RMSEA}=$ 
1 .09. Analysis showed that items from the "social functioning" subscale of the PedsQL" 4.0

2 inventory, and items from the relatedness need satisfaction and relatedness need frustration

3 subscales of the BPNSNF scale displayed high modification indices and high standardised

4 residual covariances $(> \pm 2)$, indicating considerable redundancy across items from the measures.

5 We therefore decided to omit the "social functioning" (e.g., "Other kids do not want to be my

6 friend") subscale from the PedsQL ${ }^{\mathrm{TM}} 4.0$ inventory because items from this subscale overlap

7 with those from the relatedness need frustration (e.g., "During the PE lesson I had the impression

8 that the class members I spend time with disliked me") and relatedness need satisfaction (e.g.,

9 "During the PE lesson I felt close and connected to the class members who are important to me")

10 subscales of the BPNSNF scale (Haerens et al., 2015). In addition, the "days missed from school

11 due to illness" subscale from the PedsQL ${ }^{\mathrm{TM}} 4.0$ inventory exhibited sub-optimal internal

12 consistency $(\alpha=.55)$, so we excluded it from subsequent analyses. We also allowed the

13 "relatedness need frustration" and "relatedness need satisfaction" subscales to covary based on

14 the modification indices. As a result, the final measurement model of all five latent constructs

15 and 15 indicators yielded good fit with the data $\left(\chi^{2}=547.87, \mathrm{df}=79, p<.001 ; \mathrm{CFI}=.94\right.$; NNFI

$\left.16=.92 ; \mathrm{RMSEA}=.08 ; \mathrm{CI}_{90} \mathrm{RMSEA}=.07-.08\right)$.

17 Results of the structural model estimated in the full sample demonstrated good fit with

18 the data $\left(\chi^{2}=547.87, \mathrm{df}=79, p<.001 ; \mathrm{CFI}=.94 ; \mathrm{NNFI}=.92 ; \mathrm{RMSEA}=.08 ; \mathrm{CI} 90\right.$ RMSEA $=$

$19.07-.08)$. Factor loadings of the indicators across all latent variables in the model ranged between

20.55 and .91 . In our model (see Figure 2), direct relationships between teaching behaviours and

21 HRQoL were not significant. Relationships between teaching behaviours and the mediators (i.e.,

22 need satisfaction and need frustration), and between mediator and HRQoL are reported in Table

233 and are displayed in Figure 2. Table 3 also presents the point estimates as well as the bias- 
1 corrected bootstrapped $95 \%$ confidence intervals for the mediated effects. The relationship

2 between perceived autonomy support and HRQoL was mediated only by need satisfaction $(\beta=$

$3.24, p<.001)$ and not by need frustration $(\beta=.00, p=.91)$. The relationship between perceived

4 controlling behaviour and HRQoL, mediation occurred only through need frustration $(\beta=-.30, p$

$5<.001)$ and not through need satisfaction $(\beta=.01, p=.31)$. These indirect effects resulted in

6 significant total indirect effects of perceived autonomy support $(\beta=.24, p<.01)$ and controlling

7 behaviour $(\beta=-.29, p<.001)$ on HRQoL. Also, a significant negative relationship between the

8 latent constructs for need satisfaction and need frustration $(\beta=-.32, p<.001)$, and between the

9 latent constructs for perceived autonomy support and perceived controlling behaviour $(\beta=-.54$,

$10 p<.001)$ was found. The structural model accounted for $40 \%$ of the variance in HRQoL, and

$1166 \%$ and $30 \%$ of the variance in need satisfaction and need frustration, respectively.

12
[Table 3 near here]

[Figure 2 near here]

\section{Invariance Analysis}

We tested the measurement invariance of our model across students from grades $6(n=$ $389)$ and $8(n=322)$, and across boys $(n=448)$ and girls $(n=583)$. Results for the analyses in which factor loadings, intercepts, structural paths, and structural covariances were constrained to be invariant across grade and gender are presented in Table 4. Results revealed that the changes in CFI and NNFI were $<.01$ for each successive step in the invariance routine providing evidence that each set of parameters in the routine was invariant across grade and gender.

$$
\text { [Table } 4 \text { near here] }
$$

\section{Discussion}


The purpose of the current study was to examine whether the perceptions of PE teachers' autonomy-supportive and controlling behaviours were related to students' HRQoL in PE through their respective pathways via experienced need satisfaction and need frustration. The analysis revealed that students' perceptions of their teachers' autonomy-supportive and controlling behaviours in lessons were associated with their HRQoL. In line with our hypothesis (H1), we found a significant indirect effect of students' perceptions of their teachers' autonomy-supportive behaviours on their HRQoL through need satisfaction in PE. Similarly, in line with our hypothesis (H2), we found a significant indirect effect of the perceived controlling behaviour of the teacher on students' HRQoL through need frustration. Our proposed model accounted for substantive variance in HRQoL. The findings of the current study suggest that students' HRQoL is an outcome of a "motivationally adaptive" pathway instigated by autonomy support and experiences of need satisfaction (Deci \& Ryan, 2000). In contrast, a controlling "motivationally maladaptive" pathway also exists mediated by perceived controlling behaviours from teachers (Vansteenkiste \& Ryan, 2013) and experiences of need frustration (Bartholomew et al., 2011). Results of the present study revealed no significant negative relationships between perceived autonomy support and students' need frustration, or relationships between perceived controlling behaviour and students' need satisfaction in PE, findings which were not in line with hypotheses $\mathrm{H} 3$ and $\mathrm{H} 4$. These results are inconsistent with previous findings showing relations between perceived teachers' behaviours and students' psychological needs in a context of PE (Haerens et al., 2015). More precisely, Haerens et al. (2015) found significant negative correlations between students' perceptions of their teachers' autonomy support and students' need frustration, and between students' perceptions of their teachers' controlling behaviour and need satisfaction. The inconsistencies across studies may be attributed to age differences in the 
1 participants. Participants in Haerens et al.'s study were more than two years older than

2 participants in the current study. Older students may have more comprehensive, differentiated

3 motives for participating in PE, which may be more distinct from those of their PE teacher.

4 Nevertheless, taken together, both studies provide support for the notion that need satisfaction

5 might be the unique pathway that mediates relations between the autonomy support from the

6 teacher and PE related adaptive outcomes, and that teachers' controlling behaviour undermines

7 students' HRQoL through a separate pathway. Our findings provide insight into the potentially

8 negative relation between teachers' display of perceived controlling behaviours in PE, such as

9 negative conditional regard, intimidation, and controlling use of grades, on students' need

10 frustration and, ultimately, HRQoL (Hein et al., 2015). This finding is important for practice

11 because it suggests that interventions aimed at promoting adaptive motivational outcomes and

12 HRQoL should not only focus on promoting teachers' autonomy-supportive behaviours, but on

13 reducing the display of controlling behaviours.

We also found a significant negative correlation between PE teachers' perceived autonomy-supportive behaviours and controlling behaviour, and between students' perceived need frustration and need satisfaction. This is consistent with the same relations identified in previous research (Haerens et al., 2015), although the strength of these relationships in the current study was stronger. This might be the case because we used multidimensional scales to assess teachers' autonomy-supportive and controlling behaviour, which encompassed more aspects of teachers' behaviours, increasing precision. Also, Haerens et al. assessed students' perception of their teachers' behaviour following a specific lesson, while in the current study, students were asked to refer to the PE lessons in general. Focusing on a more general context might allow students to recall more occasions where they interacted with their teacher. Finally, 
1 the proposed model was also found to be invariant across gender and grade (H5), which indicates

2 that boys and girls, and students in grades $6-8$, responded to the items in a similar fashion. It

3 also indicates that the pattern of relations between constructs in the proposed model is consistent

4 across gender and grade and, therefore, the relations may generalise to these age groups and

5 across boys and girls.

6 While previous studies have tested the indirect effect of perceived PE teachers' autonomy

7 support on students' HRQoL (Koka, 2014; Standage \& Gillison, 2007; Standage et al., 2012), the

8 current study adds to the literature by providing the evidence that perceived teachers' controlling

9 behaviour was found to be negatively associated with students' HRQoL through psychological need frustration. Based on current findings, future studies might focus on examining effects of

11 potential interventions aimed at decreasing students' perceptions of their teachers' controlling

12 behaviour. For example, it is argued by De Meyer et al. (2014) that controlling behaviour could

13 be perceived by students strongly despite the relatively infrequent use of controlling behaviour

14 by teachers. It is possible that even minimal exposure to controlling behaviour might impact

15 students' perceived need frustration and HRQoL. Therefore, one might argue that it is important

16 not only to increase teachers' autonomy-supportive behaviour but also decrease teachers'

17 controlling behaviour to minimise frustration of psychological needs. Results of the current study 18 suggest that PE teachers' behaviour with respect to increasing students' HRQoL does not involve 19 only increasing autonomy-supportive strategies, but also decreasing controlling behaviour. This 20 finding might have implications for the design of intervention programs aimed at promoting

21 adaptive outcomes in PE. Such interventions should focus on fostering teachers' autonomy-

22 supportive behaviours as well as minimising teachers' display of controlling behaviours.

23 Although there is a stipulation that autonomy-support interventions programs for PE teachers 
1 should minimise controlling behaviour ( $S u$ \& Reeve, 2011), little attention has been paid to this

2 aspect.

3 Implications for Practice

4 The perceived autonomy support construct comprised three different dimensions,

5 organisational, procedural, and cognitive (Tilga et al., 2017). Considering the importance of all

6 three dimensions and current findings, we suggest some specific implications for practising PE

7 teachers to promote HRQoL in students. First, PE teachers are encouraged to adopt

8 organisational autonomy support (e.g., allowing students to choose their sport equipment;

9 accepting students' solutions to learning exercises). This form of autonomy support has been

10 shown to be related students' feelings of autonomy need satisfaction in PE lessons (Tilga et al.,

11 2017), and may further enhance students' levels of HRQoL. Second, PE teachers are

12 recommended to display cognitive autonomy support (e.g., allowing students to express their

13 own opinions; providing responses to students when they express their opinion). This form of

14 autonomy support may facilitate students' competence need satisfaction in PE lessons (Tilga et

15 al., 2017) and their HRQoL. Third, teachers should adopt behaviours categorised as procedural

16 autonomy support (e.g., explaining the effect of exercise on health; guiding students toward

17 finding solutions to problems without directly revealing the answer) that is associated with

18 higher perception of students' feelings of relatedness and may result in higher levels of HRQoL.

Similar to the perceived autonomy support construct, the perceived teachers' controlling

20 behaviour construct also comprised three dimensions (Hein et al., 2015). Accordingly, some

21 specific suggestions can be provided to practising PE teachers on which behaviours should be

22 avoided in their classes so as not to diminish their students' HRQoL. PE teachers would do well

23 to avoid behaviours such as being less supportive to students when they do not perform well (i.e., 
1

negative conditional regard); shouting at students in front of others to make them comply (i.e., intimidating behaviour); and promising to give students a good grade if they behave well (i.e., controlling use of grades). Such behaviours have shown to be related to higher basic psychological need thwarting in students (Hein et al., 2015), which may undermine HRQoL. Drawn from the above, teachers must be aware that students' perceptions of the autonomy-supportive and controlling behaviours that they display in PE lessons will be have positively and negatively related, respectively, to their students' HRQoL. Moreover, teachers must consider that the mechanism behind effects of teachers' autonomy-supportive and controlling behaviour in PE on students' HRQoL is via the perceived satisfaction and frustration of psychological needs, respectively, in the context of PE. This knowledge is important for PE teachers because if they display autonomy-supportive behaviours to their students in lessons, their students are likely experience higher levels of HRQoL. The mechanism behind this relationship is that autonomy-supportive behaviour is likely to fulfil students' psychological needs in lessons. On the other hand, if PE teachers display controlling behaviours to their students, their students are likely to report lower levels of HRQoL. The process behind this relationship is that controlling behaviours frustrate students' psychological needs in lessons.

\section{Strengths and Limitations}

The current study used a large sample size of secondary school children and tested an a priori specified model based on theory using a rigorous confirmatory approach (Hagger, Gucciardi, \& Chatzisarantis, 2017). However, the study is not without limitations, and these should be acknowledged. First, our study was conducted on a sample of students with a relatively narrow age range. Future analyses should seek to test the validity of our model in a sample of students with a more diverse age range. Second, our model was tested in a sample 
1 from a single cultural group. Further evidence for the validity and reliability of our proposed

2 model would be provided by testing the invariance of the model across different cultural groups

3 (c.f., Hagger, Biddle, Chow, Stambulova, \& Kavussanu, 2003; Sheldon et al., 2004). Third, the

4 current study provided a cross-sectional examination of our proposed model, which is not

5 informative of the causal relations between these constructs. Longitudinal studies adopting panel

6 designs are needed to determine whether the model is consistent across time and to test

7 reciprocal effects among model constructs. Fourth, we relied exclusively on self-report measures

8 of study constructs, which has potential to introduce common method variance and may inflate

9 associations among constructs (Podsakoff, MacKenzie, Lee, \& Podsakoff, 2003). Future research

10 should consider alternative measures, for example, behavioural observation to provide

11 converging evidence for the proposed relationships. Another limitation is that the subscale "days

12 missed from school due to illness" from the PedsQL ${ }^{\mathrm{TM}} 4.0$ inventory exhibited sub-optimal

13 internal consistency $(\alpha=.55)$, also evident by previous studies (e.g., Reinfjell, Dishet, Veenstra,

14 \& Vikan, 2006; Viira \& Koka, 2011). The reason for this might be that one item (i.e., "I miss

15 school to go to the doctor or hospital") of this subscale might not express the reason of illness for

16 the absence from school, because regular health check might also be the case for seeing the

17 doctor. Future studies should consider revising this item to provide sufficient internal

18 consistency of subscale "days missed from school due to illness". Finally, the current model was

19 tested only in a PE context. The future studies could test whether or not our proposed model is

20 applicable to students of other subjects (e.g., math, science, humanities; Hagger, Sultan,

21 Hardcastle, \& Chatzisarantis, 2015; Hagger \& Hamilton, 2018; Wang, 2012), and in other

22 settings such as sport or social interactions. 

supportive behaviours in PE lessons but also minimise displays of controlling behaviours.

3 Together, these adjustments to teaching style may maximise the potential for students'

4 psychological needs to be satisfied, minimise need thwarting, and facilitate perceived HRQoL.

\section{Disclosure Statement}

$6 \quad$ No potential conflict of interest was reported by the authors. 


\section{References}

Amoura, C., Berjot, S., Gillet, N., Caruana, S., \& Finez, L. (2015). Effects of autonomysupportive and controlling styles on situational self-determined motivation: Some unexpected results of the commitment procedure. Psychological Reports: Employment Psychology \& Marketing, 116, 33-59. doi: 10.2466/14.PRO.116k10w7

Anderson, J. C., \& Gerbing, D. W. (1988). Structural equation modeling in practice: A review and recommended two-step approach. Psychological Bulletin, 103, 411-423. doi: $10.1037 / 0033-2909.103 .3 .411$

Assor, A., Kaplan, H., Kanat-Maymon, Y., \& Roth, G. (2005). Directly controlling teacher behaviors as predictors of poor motivation and engagement in girls and boys: The role of anger and anxiety. Learning and Instruction, 15, 397-413. doi: 10.1016/j.learninstruc.2005.07.008

Bartholomew, K. J., Ntoumanis, N., Ryan, R. M., Bosch, J. A., \& Thøgersen-Ntoumani, C. (2011). Self-determination theory and diminshed functioning: The role of interpersonal control and psychological need thwarting. Personality and Social Psychology Bulletin, 37, 1459-1473. doi: 10.1177/0146167211413125

Bartholomew, K. J., Ntoumanis, N., \& Thøgersen-Ntoumani, C. (2010). The controlling interpersonal style in a coaching context: Development and initial validation of a psychometric scale. Journal of Sport and Exercise Psychology, 32, 193-216.

Bisegger, C., Cloetta, B., von Rueden, U., Abel, T., Ravens-Sieberer, U., \& the European Kidscreen Group (2005). Health-related quality of life: Gender differences in childhood and adolescence. Social-and Preventive Medicine, 50, 281-291. doi: 10.1007/s00038-005-4094- 
Teachers' Behaviour and Students' HRQoL

Byrne, B. M. (2010). Structural equation modeling with AMOS: Basic concepts, applications, and programming (2nd ed.). New York, NY: Routledge.

Cerin, E., \& Mac Kinnon, P. D. (2008). A commentary on current practice in mediation variable analyses in behavioural nutrition and physical activity. Public Health Nutrition, 12, 11821188. doi: $10.1017 / \mathrm{S} 1368980008003649$

Chen, B., Vansteenkiste, M., Beyers, W., Boone, L., Deci, E. L., Van der Kaap-Deeder, J., ... \& Verstuyf, J. (2015). Basic psychological need satisfaction, need frustration, and need strength across four cultures. Motivation and Emotion, 39, 216-236. doi: 10.1007/s11031014-9450-1

Cheung, G. W., \& Rensvold, R. B. (2002). Evaluating goodness-of-fit indexes for testing measurement invariance. Structural Equation Modeling: A Multidisciplinary Journal, 9, 233-255. doi: 10.1207/S15328007SEM0902_5

De Meyer, J., Soenens, B., Aelterman, N., De Bourdeaudhuij, I., \& Haerens, L. (2016). The different faces of controlling teaching: Implications of a distinction between externally and internally controlling teaching for students' motivation in physical education. Physical Education and Sport Pedagogy, 21, 632-652. doi: 10.1080/17408989.2015.1112777

De Meyer, J., Tallir, I. B., Soenens, B., Vansteenkiste, M., Aelterman, N., Speleers, L., \& Haerens, L. (2014). Does observed controlling teaching behavior relate to students' motivation in physical education? Journal of Educational Psychology, 106, 541-554. doi: $10.1037 / \mathrm{a} 0034399$

Deci, E. L., Eghrari, H., Patrick, B. C., \& Leone, D. R. (1994). Facilitating internalization: The self-determination theory perspective. Journal of Personality, 62, 119-142. doi: 10.1111/j.1467-6494.1994.tb00797.x 
Deci, E. L., \& Ryan, R. M. (1985). Intrinsic motivation and self-determination in human behavior. New York: Plenum.

Deci, E. L., \& Ryan, R. M. (2002). Self-determination research: Reflections and future directions. In E. L. Deci, \& R. M. Ryan (Eds.), Handbook of self-determination research (pp. 431-441). Rochester, NY: University of Rochester Press.

Deci, E. L., \& Ryan, R. M. (2000). The "what" and "why" of goal pursuits: Human needs and the self-determination of behavior. Psychological Inquiry, 11, 227-268. doi: 10.1207/S15327965PLI1104_01

Durlak, J. A., Weissberg, R. P., Dymnicki, A. B., Taylor, R. D., \& Schellinger, K. B. (2011). The impact of enhancing students' social and emotional learning: A metaanalysis of schoolbased universal interventions. Child Development, 82, 405-432. doi: 10.1111/j.14678624.2010.01564.x

George, D. \& Mallery, M. (2010). SPSS for windows step by step: A simple guide and reference. Boston, MA: Pearson.

Haerens, L., Aelterman, N., Vansteenkiste, M., Soenens, B., \& Van Petegem, S. (2015). Do perceived autonomy-supportive and controlling teaching relate to physical education students' motivational experiences through unique pathways? Distinguishing between the bright and dark side of motivation. Psychology of Sport and Exercise, 16, 26-36. doi: 10.1016/j.psychsport.2014.08.013

Hagger, M. S. (2014). Avoiding the ‘déjà-variable’ phenomenon: Social psychology needs more guides to constructs. Frontiers in Psychology, 5, 1-2, article no. 52. doi: 10.3389/fpsyg.2014.00052 
Teachers' Behaviour and Students' HRQoL

1 Hagger, M. S., Biddle, S. J. H., Chow, E. W., Stambulova, N., \& Kavussanu, M. (2003).

Physical self-perceptions in adolescence: Generalizability of a hierarchical multidimensional model across three cultures. Journal of Cross-Cultural Psychology, 34, 611-628. doi: $10.1177 / 0022022103255437$

Hagger, M. S., Gucciardi, D. F., \& Chatzisarantis, N. L. D. (2017). On nomological validity and auxiliary assumptions: The importance of simultaneously testing effects in social cognitive theories applied to health behavior and some guidelines. Frontiers in Psychology, 8, 1933. doi: 10.3389/fpsyg.2017.01933

Hagger, M. S., \& Hamilton, K. (2018). Motivational predictors of students' participation in outof-school learning activities and academic attainment in science: An application of the transcontextual model using Bayesian path analysis. Learning and Individual Differences, 67, 232-244. doi: 10.1016/j.lindif.2018.09.002

Hagger, M. S., Sultan, S., Hardcastle, S. J., \& Chatzisarantis, N. L. D. (2015). Perceived autonomy support and autonomous motivation toward mathematics activities in educational and out-of-school contexts is related to mathematics homework behavior and attainment. Contemporary Educational Psychology, 41, 111-123. doi: 10.1016/j.cedpsych.2014.12.002

Hayes, A. F. (2018). Introduction to mediation, moderation, and conditional process analysis. (2nd Ed.). New York: The Guilford Press.

Hayes, A. F., \& Scharkow, M. (2013). The relative trustworthiness of inferential test of the indirect effect in statistical mediation analysis: Does method really matter? Psychological Science, 24, 1918-1927. doi: 10.1177/0956797613480187

Hein, V. \& Caune, A. (2014). Relationships between perceived teacher's autonomy support, effort and physical self-esteem. Kinesiology, 46, 44-52. 
1 Hein, V., Emeljanovas, A., \& Mieziene, B. (2018). A cross-cultural validation of the controlling teacher behaviours scale in physical education. European Physical Education Review, 24, 209-224. doi: 1356336X16681821

4

Hein, V., Koka, A., \& Hagger, S. M. (2015). Relationships between perceived teachers' controlling behaviour, psychological need thwarting, anger and bullying behaviour in highschool students. Journal of Adolescence, 42, 103-114. doi:

10.1016/j.adolescence.2015.04.003

Hu, L. T., \& Bentler, P. M. (1999). Cutoff criteria for fit indexes in covariance structure analysis: Conventional criteria versus new alternatives. Structural Equation Modeling: A Multidisciplinary Journal, 6, 1-55. doi: 10.1080/10705519909540118

Jang, H., Reeve, J., \& Deci, E. L. (2010). Engaging students in learning activities: It is not autonomy support or structure but autonomy support and structure. Journal of Educational Psychology, 102, 588-600. doi: 10.1037/a0019682

Koka, A. (2014). The relative roles of teachers and peers on students' motivation in physical education and its relationship to self-esteem and health-related quality of life. International Journal of Sport Psychology, 45, 187-213. doi: 10.7352/IJSP2014.45.187

McLachlan, S., \& Hagger, M. S. (2010). Effects of an autonomy-supportive intervention on tutor behaviors in a higher education context. Teaching and Teacher Education, 26, 1205-1211. doi: 10.1016/j.tate.2010.01.006

Meade, T., \& Dowswell, E. (2016). Adolescents' health-related quality of life (HRQoL) changes over time: A three year longitudinal study. Health and Quality of Life Outcomes, 14, 14. doi: $10.1186 / \mathrm{s} 12955-016-0415-9$ 
Teachers' Behaviour and Students' HRQoL

1 Mouratidis, A. A., Vansteenkiste, M., Sideridis, G., \& Lens, W. (2011). Vitality and interestenjoyment as a function of class-to-class variation in need-supportive teaching and pupils' autonomous motivation. Journal of Educational Psychology, 103, 353-366. http://dx.doi.org/10.1037/a0022773

Ntoumanis, N. (2005). A prospective study of participation in optional school physical education using a self-determination theory framework. Journal of Educational Psychology, 97, 444453. doi: 10.1037/0022-0663.97.3.444

Pihu, M., Hein, V., Koka, A., \& Hagger, M. S. (2008). How students' perceptions of teacher's autonomy-supportive behaviours affect physical activity behaviour: An application of the trans-contextual model. European Journal of Sport Science, 8, 193-204. doi: $10.1080 / 17461390802067679$

Podsakoff, P. M., MacKenzie, S. B., Lee, J. Y., \& Podsakoff, N. P. (2003). Common method biases in behavioral research: A critical review of the literature and recommended remedies. Journal of Applied Psychology, 88, 879-903. doi: 10.1037/0021-9101.88.5.879

Preacher, K. J., \& Hayes, A. F. (2008). Asymptotic and resampling strategies for assessing and comparing indirect effects in multiple mediator models. Behavior Research Methods, 40, 879-891. doi: 10.3758/BRM.40.3.879

Reeve, J. (2009). Why teachers adopt a controlling motivating style toward students and how they can become more autonomy supportive. Educational Psychologist, 44, 159-175. doi: $10.1080 / 00461520903028990$

Reeve J., \& Halusic, M. (2009). How K-12 teachers can put self-determination theory principles into practice. Theory and Research in Education, 7, 145-154. doi:

$10.1177 / 1477878509104319$ 
Teachers' Behaviour and Students' HRQoL

1 Reeve, J., \& Jang, H. S. (2006). What teachers say and do to support students' autonomy during a learning activity. Journal of Educational Psychology, 98, 209-218. doi: 10.1037/00220663.98.1.209

Reinfjell, T., Disheth, T. H., Veenstra, M., \& Vikan, A. (2006). Measuring health-related quality of life in young adolescents: Reliability and validity in the Norwegian version of the pediatric quality of life inventory ${ }^{\mathrm{TM}}$ version $4.0\left(\mathrm{PedsQL}^{\mathrm{TM}}\right)$ generic core scales. Health and Quality of Life Outcomes, 4, 61. doi: 10.1186/1477-7525-4-61

Ryan, R. M., \& Deci, E. L. (2008). Self-determination theory and the role of basic psychological needs in personality and the organization of behavior. In O. P. John, R. W. Robbins \& L. A. Pervin (Eds.), Handbook of personality Theory and research (pp. 654-678). New York, NY: The Guilford Press.

Ryan, R. M., \& Deci, E. L. (2017). Self-determination theory: Basic psychological needs in motivation, development, and wellness. New York: Guilford Press.

Sheldon, K. M., Elliot, A. J., Kim, Y., \& Kasser, T. (2001). What's satisfying about satisfying events? Comparing ten candidate psychological needs. Journal of Personality and Social Psychology, 80, 325-339. doi: 10.1037//0022-3514.80.2.325

Sheldon, K. M., Elliot, A. J., Ryan, R. M., Chirkov, V., Kim, Y., Wu, C., ... \& Sun, Z. (2004). Self-concordance and subjective well-being in four cultures. Journal of Cross-Cultural Psychology, 35, 209-223. doi: 10.1177/0022022103262245

Shumaker, S. A., \& Naughton, M. J. (1995). The international assessment of health-related quality of life: A theoretical perspective. In S. A. Shumaker \& R. A. Berzon (Eds.), The international assessment of health-related quality of life: Theory, translation, measurement and analysis (pp. 3-10). Oxford, UK: Rapid Communication. 
Teachers’ Behaviour and Students' HRQoL

1 Soenens, B., Sierens, E., Vansteenkiste, M., Dochy, F., \& Goossens, L. (2012). Psychologically controlling teaching: Examining outcomes, antecedents, and mediators. Journal of Educational Psychology, 104, 108-120. doi: http://dx.doi.org/10.1037/a0025742

Standage, M., Duda, J. L., \& Ntoumanis, N. (2005). A test of self-determination theory in school physical education. British Journal of Educational Psychology, 75, 411-433. doi:10.1348/000709904X22359

Standage, M., \& Gillison, F. (2007). Students' motivational responses toward school physical education and their relationship to general self-esteem and health-related quality of life. Psychology of Sport and Exercise, 8, 704-721. doi: 10.1016/j.psychsport.2006.12.004

Standage, M., Gillison, F. B., Ntoumanis, N., \& Treasure, D. C. (2012). Predicting students' physical activity and health-related well-being: A prospective cross-domain investigation of motivation across school physical education and exercise settings. Journal of Sport and Exercise Psychology, 34, 37-60.

Su, Y.-L., \& Reeve, J. (2011). A Meta-analysis of the effectiveness of intervention programs designed to support autonomy. Educational Psychology Review, 23, 159-188. doi: $10.1007 / \mathrm{s} 10648-010-9142-7$

Tessier, D., Sarrazin, P., \& Ntoumanis, N. (2008). The effects of an experimental programme to support students' autonomy on the overt behaviors of physical education teachers. European Journal of Psychology of Education, 23, 239-253. doi: 10.1007/bf03172998

Tilga, H., Hein, V., \& Koka, A. (2017). Measuring the perception of the teachers' autonomysupportive behavior in physical education: Development and initial validation of a multidimensional instrument. Measurement in Physical Education and Exercise Science, 21, 244255. doi: 10.1080/1091367X.2017.1354296 
Teachers' Behaviour and Students' HRQoL

1

Van den Berghe, L., Vansteenkiste, M., Cardon, G., Kirk, D., \& Haerens, L. (2014). Research on self-determination in physical education: Key findings and proposals for future research. Physical Education and Sport Pedagogy, 19, 97-121. doi:10.1080/17408989.2012.732563

Vansteenkiste, M., \& Ryan, R. M. (2013). On psychological growth and vulnerability: Basic psychological need satisfaction and need frustration as a unifying principle. Journal of Psychotherapy Integration, 23, 263-280. doi: 10.1037/a0032359

Varni, J. W., Burwinkle, T. M., Seid, M., \& Skarr, D. (2003). The PedsQL 4.0 as a pediatric population health measure: Feasibility, reliability, and validity. Ambulatory Pediatrics, 3, 329-341. doi: 10.1367/1539-4409(2003)003<0329:TPAAPP>2.0.CO;2

Varni, J. W., Seid, M., \& Kurtin, P. S. (2001). PedsQL (TM) 4.0: Reliability and validity of the pediatric quality of life inventory (TM) version 4.0 generic core scales in healthy and patient populations. Medical Care, 39, 800-812. doi: 10.1097/00005650-200108000-00006

Viira, R., \& Koka, A. (2011). Health-related quality of life of Estonian adolescents: Reliability and validity of the PedsQL ${ }^{\text {TM }} 4.0$ generic core scales in Estonia. Acta Paediatrica, 100, 1043-1047. doi: 10.1111/j.1651-2227.2011.02193.x

Wang, M. T. (2012). Educational and career interests in math: A longitudinal examination of the links between classroom environment, motivational beliefs, and interests. Developmental Psychology, 48, 1643-1657. doi: 10.1037/a0027247

Widaman, K. F. (1985). Hierarchically nested covariance structure models for multitraitmultimethod data. Applied Psychological Measurement, 9, 1-26. doi: $10.1177 / 014662168500900101$ 
Table 1

Descriptive Statistics and Scale Reliabilities for Study Variables

\begin{tabular}{|c|c|c|c|c|c|c|c|c|c|c|c|c|c|c|c|}
\hline \multirow{2}{*}{ Variable } & \multicolumn{15}{|c|}{ Correlation } \\
\hline & 1 & 2 & 3 & 4 & 5 & 6 & 7 & 8 & 9 & 10 & 11 & 12 & 13 & 14 & 15 \\
\hline 1. Cognitive autonomy support & - & & & & & & & & & & & & & & \\
\hline 2. Procedural autonomy support & .72 & - & & & & & & & & & & & & & \\
\hline 3.Organisational autonomy support & .80 & .72 & - & & & & & & & & & & & & \\
\hline 4. Negative conditional regard & -.48 & -.36 & -38 & - & & & & & & & & & & & \\
\hline 5. Controlling use of grades & -.13 & -.03 & -.06 & .47 & - & & & & & & & & & & \\
\hline 6. Intimidation & -.45 & -.33 & -.34 & .61 & .46 & - & & & & & & & & & \\
\hline 7. Autonomy satisfaction & .70 & .63 & .66 & -.37 & -.05 & -.32 & - & & & & & & & & \\
\hline 8. Competence satisfaction & .59 & .53 & .53 & -.33 & -.04 & -.25 & .75 & - & & & & & & & \\
\hline 9. Relatedness satisfaction & .37 & .33 & .30 & -.15 & .06 & -.15 & .48 & .48 & - & & & & & & \\
\hline 10. Autonomy frustration & -.27 & -.18 & -20 & .36 & .33 & .31 & -.26 & -.21 & -.05 & - & & & & & \\
\hline 11. Competence frustration & -.27 & -.15 & -18 & .39 & .28 & .30 & -.27 & -.40 & -.17 & .51 & - & & & & \\
\hline 12. Relatedness frustration & -.16 & -.10 & -.09 & .26 & .17 & .27 & -.13 & -.21 & -.40 & .27 & .53 & - & & & \\
\hline 13. Physical health & .22 & .17 & .16 & -.19 & -.09 & -.17 & .25 & .38 & .23 & -.20 & -.43 & -.34 & - & & \\
\hline 14. Emotional functioning & .22 & .18 & .16 & -.22 & -.13 & -.21 & .25 & .33 & .22 & -.21 & -.43 & -.35 & .57 & - & \\
\hline 15. School-related functioning & .18 & .12 & .11 & -.14 & -.11 & -.16 & .17 & .19 & .24 & -.09 & -.26 & -.25 & .48 & .47 & - \\
\hline$M$ & 4.85 & 4.93 & 4.29 & 3.39 & 3.47 & 2.34 & 4.35 & 4.91 & 4.90 & 4.18 & 3.46 & 2.63 & 73.08 & 69.99 & 67.21 \\
\hline$S D$ & 1.32 & 1.24 & 1.28 & 1.57 & 1.46 & 1.54 & 1.43 & 1.36 & 1.47 & 1.18 & 1.51 & 1.46 & 18.03 & 21.15 & 21.55 \\
\hline$\alpha$ & .86 & .81 & .83 & .78 & .71 & .84 & .88 & .87 & .88 & .64 & .86 & .89 & .81 & .75 & .69 \\
\hline
\end{tabular}

significant at the $p<.01$ level. 
Table 2

Correlations Among Latent Study Variables

\begin{tabular}{lcccc}
\hline \multicolumn{1}{c}{ Variable } & \multicolumn{4}{c}{ Correlation } \\
\cline { 2 - 5 } & 1 & 2 & 3 & 4 \\
\hline 1. Autonomy support & - & & & \\
2. Controlling behaviour & -.54 & - & - & \\
3. Need satisfaction & .81 & -.41 & -.39 & - \\
4. Need frustration & -.30 & .55 & .41 & -.60 \\
5. HRQoL & .29 & -.32 & \\
\hline
\end{tabular}

Note. $N=1031$. All the correlations are significant at the $p<.01 ; \mathrm{HRQoL}=$ Health-related quality of life. 
Table 3

Standardised Parameter Estimates and Variability Statistics for the Multiple-Mediator Model of

the Effect of Students' Perceptions of Their Teacher's Behaviour on Their HRQoL with Need

Satisfaction and Frustration as Mediators

\begin{tabular}{|c|c|c|c|c|c|c|}
\hline \multirow[t]{2}{*}{$\mathrm{H}$} & \multirow[t]{2}{*}{ Independent variable } & \multirow{2}{*}{$\begin{array}{l}\text { Dependent } \\
\text { variable }\end{array}$} & \multirow[t]{2}{*}{ Mediator(s) } & \multirow[t]{2}{*}{$\beta$} & \multicolumn{2}{|c|}{$95 \% \mathrm{CI}$} \\
\hline & & & & & $\mathrm{LL}$ & $\mathrm{UL}$ \\
\hline & \multicolumn{6}{|l|}{ Direct effects } \\
\hline & Perceived autonomy support & Need satisfaction & - & $0.83^{* * * *}$ & 0.77 & 0.88 \\
\hline & Perceived autonomy support & HRQoL & - & -0.08 & -0.25 & 0.09 \\
\hline H3 & Perceived autonomy support & Need frustration & - & -0.00 & -0.09 & 0.08 \\
\hline \multirow[t]{6}{*}{$\mathrm{H} 4$} & Perceived controlling behaviour & Need satisfaction & - & 0.03 & -0.03 & 0.10 \\
\hline & Perceived controlling behaviour & HRQoL & - & 0.06 & -0.07 & 0.18 \\
\hline & Perceived controlling behaviour & Need frustration & - & $0.55^{* * * *}$ & 0.45 & 0.64 \\
\hline & Need satisfaction & HRQoL & - & $0.29^{* * * *}$ & 0.12 & 0.46 \\
\hline & Need frustration & HRQoL & - & $-0.55^{* * *}$ & -0.65 & -0.44 \\
\hline & \multicolumn{6}{|l|}{ Indirect effects } \\
\hline \multirow[t]{2}{*}{$\mathrm{H} 1$} & Perceived autonomy support & HRQoL & Need satisfaction & $0.24^{* * * *}$ & 0.09 & 0.39 \\
\hline & Perceived autonomy support & HRQoL & Need frustration & 0.00 & -0.04 & 0.05 \\
\hline \multirow[t]{2}{*}{$\mathrm{H} 2$} & Perceived controlling behaviour & HRQoL & Need frustration & $-0.30^{* * *}$ & -0.42 & -0.22 \\
\hline & Perceived controlling behaviour & HRQoL & Need satisfaction & 0.01 & -0.01 & 0.04 \\
\hline \multicolumn{7}{|c|}{ Sum of indirect effects } \\
\hline & Perceived autonomy support & HRQoL & $\begin{array}{l}\text { Need satisfaction } \\
\text { Need frustration }\end{array}$ & $0.24^{* * *}$ & 0.09 & 0.39 \\
\hline & Perceived controlling behaviour & HRQoL & $\begin{array}{l}\text { Need frustration } \\
\text { Need satisfaction }\end{array}$ & $-0.29^{* * *}$ & -0.39 & -0.21 \\
\hline \multicolumn{7}{|c|}{ Total effects } \\
\hline & Perceived autonomy support & HRQoL & & $0.16^{* *}$ & 0.06 & 0.25 \\
\hline & Perceived controlling behaviour & HRQoL & & $-0.23^{* * *}$ & -0.33 & -0.13 \\
\hline
\end{tabular}

Note. ${ }^{* *} p<.01 ; * * * p<.001 . \mathrm{H}=$ Hypothesis; $\beta=$ Standardised parameter estimate; $\mathrm{HRQoL}=$

Health-related quality of life; $95 \% \mathrm{CI}=95 \%$ confidence intervals of parameter estimates; $\mathrm{LL}=$

Lower limit of $95 \% \mathrm{CI}$; UL= Upper limit of $95 \% \mathrm{CI}$. 
Table 4

The Goodness-of-Fit Indices for Structural Models and Comparisons for Multisample Structural Equation Models

\begin{tabular}{|c|c|c|c|c|c|c|c|c|}
\hline Models & $\chi^{2}$ & df & CFI & NNFI & RMSEA & CI90RMSEA & $\Delta \mathrm{CFI}$ & $\triangle \mathrm{NNFI}$ \\
\hline \multicolumn{9}{|l|}{ Gender } \\
\hline SEM for boys & 317.204 & 79 & .928 & .905 & .082 & .073-.092 & & \\
\hline SEM for girls & 358.346 & 79 & .935 & .914 & .078 & $.070-.086$ & & \\
\hline Baseline & 675.563 & 158 & .932 & .910 & .056 & $.052-.061$ & & \\
\hline FL invariant & 696.980 & 168 & .931 & .913 & .055 & $.051-.060$ & .001 & .003 \\
\hline FL, intercepts invariant & 736.868 & 183 & .927 & .917 & .054 & $.050-.058$ & .004 & .004 \\
\hline FL, intercepts, structural paths invariant & 752.808 & 191 & .926 & .919 & .053 & $.049-.058$ & .001 & .002 \\
\hline FL, intercepts, structural paths, FV invariant & 753.977 & 193 & .926 & .920 & .053 & $.049-.057$ & .000 & .001 \\
\hline \multicolumn{9}{|l|}{ Grade } \\
\hline SEM for $6^{\text {th }}$ Grade students & 299.390 & 79 & .922 & .896 & .085 & $.075-.095$ & & \\
\hline SEM for $8^{\text {th }}$ Grade students & 251.787 & 79 & .931 & 909 & .083 & $.071-.094$ & & \\
\hline Baseline & 551.178 & 158 & .926 & .902 & .059 & $.054-.065$ & & \\
\hline FL invariant & 564.212 & 168 & .926 & .907 & .058 & $.052-.063$ & .000 & .005 \\
\hline FL, intercepts invariant & 602.871 & 183 & .921 & .910 & .057 & $.052-.062$ & .005 & .003 \\
\hline FL, intercepts, structural paths invariant & 619.045 & 191 & .920 & .912 & .056 & $.051-.061$ & .001 & .002 \\
\hline FL, intercepts, structural paths, FV invariant & 619.252 & 193 & .920 & .913 & .056 & $.051-.061$ & .000 & .001 \\
\hline
\end{tabular}

Note. $\chi^{2}=$ chi square; $\mathrm{df}=$ degrees of freedom; CFI = comparative fit index; NNFI = non-normed fit index; RMSEA = root mean

square error of approximation; $\mathrm{CI}{ }_{90} \mathrm{RMSEA}=90 \%$ confidence intervals for the RMSEA; $\Delta \mathrm{CFI}=$ the change in $\mathrm{CFI} ; \Delta \mathrm{NNFI}=$ the change in NNFI; SEM = structural equation model; FL = factor loading; FV = factor covariance. 


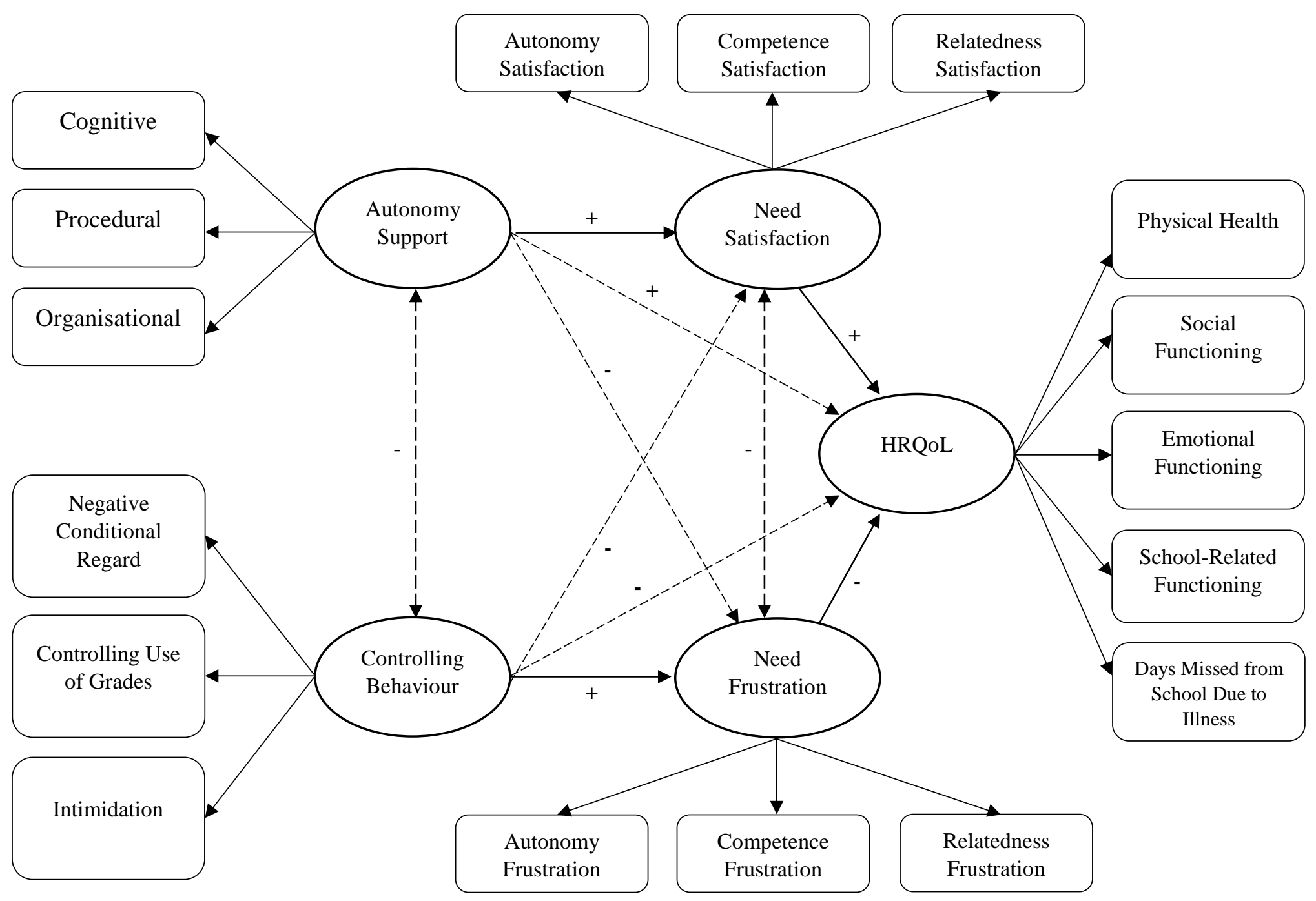

Figure 1. The hypothesised model demonstrating expected relationships. Broken lines point to paths that are set free in the test of the model. Note. $\mathrm{HRQ} \mathrm{LL}=$ Health-related quality of life. 


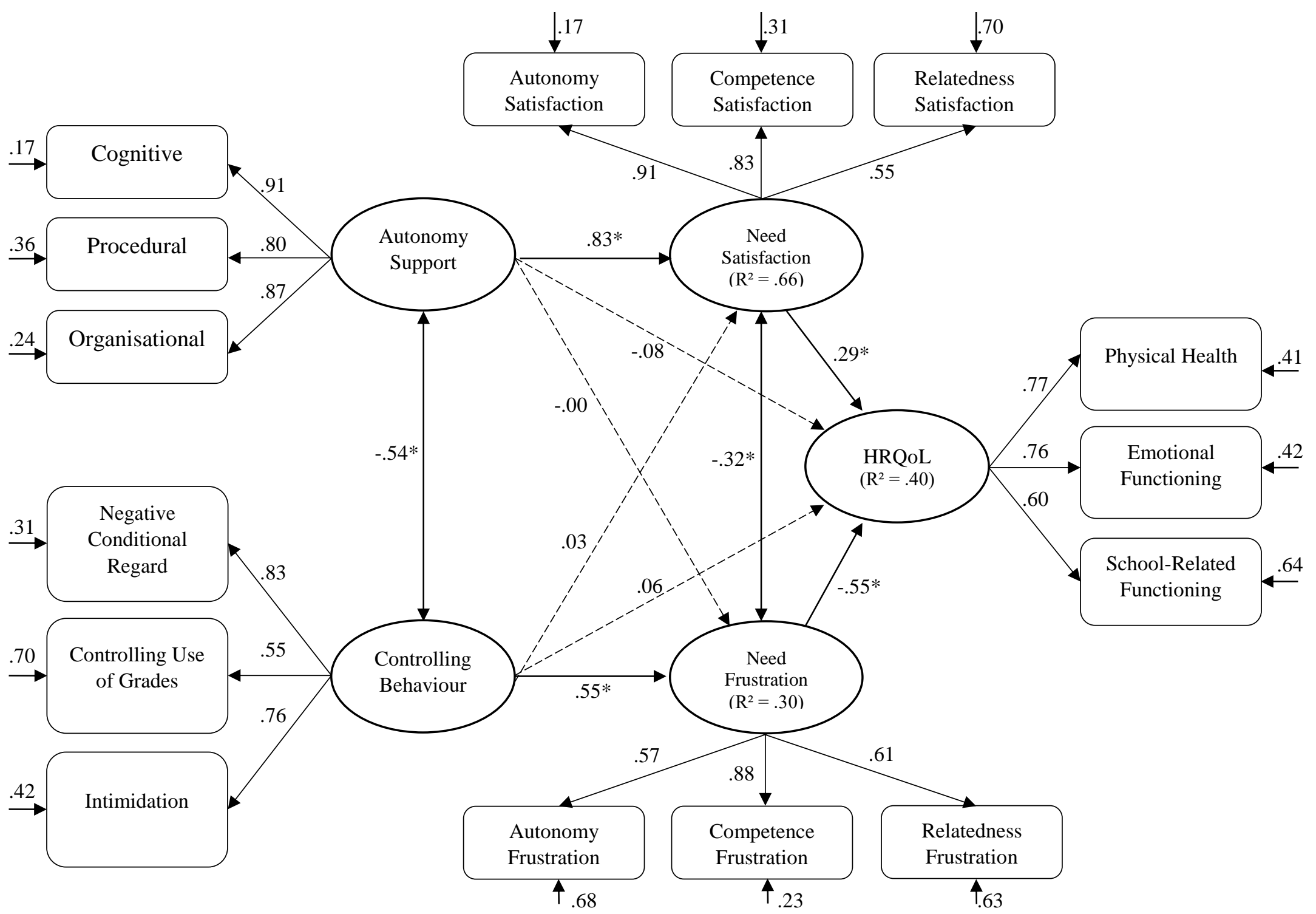

Figure 2. The structural equation model measuring the relationships from students' perceived autonomy supportive and controlling behaviour to HRQoL through need satisfaction and need frustration. Note. ${ }^{*} p<.001$; Broken lines represent not significant relations. HRQoL = Health-related quality of life. 